\title{
Uma análise da proposta do Plano Brasil sem Miséria
}

\section{A proposal analysis of the Plan no Poverty Brazil}

\author{
Angela Maria Moura Costa Prates* \\ "A história da sociedade até aos nossos dias \\ é a história da luta de classes"
}

(Karl Marx).

\begin{abstract}
Resumo: Em todas as sociedades parte da humanidade foi submetida a condições de pobreza. No entanto, com o advento do sistema capitalista ela ganhou maiores proporções. Isso passou a despertar a preocupação dos governos e agências internacionais. Nesse sentido, o presente artigo tem como objetivo discutir a proposta de combate à pobreza no Brasil através do Plano Brasil Sem Miséria, o qual pretende tirar da extrema pobreza mais de 16 milhões de brasileiros. Trata-se de uma pesquisa bibliográfica e análise documental. O Plano Brasil Sem Miséria é uma iniciativa governamental para combater a pobreza extrema no país, porém, na forma como vem sendo apresentado, não mexe nas estruturas geradoras da pobreza, uma vez que foca as ações na extrema pobreza com um corte de renda bem definido. Isso gera preocupação quanto à efetividade do combate à pobreza no país.
\end{abstract}

Palavras-chave: Pobreza. Combate. Plano Brasil Sem Miséria.

\begin{abstract}
In all society levels part of the mankind was submitted to poverty conditions. However, with the capitalism system it gained great proportions. It caused awareness and concern from the governments and international agencies. Thus, this paper has its goal in discussing the proposal about poverty combating in Brazil by the "Plan No Poverty Brazil" which intends to take out from poverty more than 16 million of Brazilian. It is about a bibliographic research and documental analysis. The "Plan No Poverty Brazil is a governmental initiative to combat the extreme poverty in the country, however, as it has been presented, do not work efficiently in the structures that generate poverty, since the focus in actions of extreme poverty with a cutting income well defined. It turns out to the concerning about the effectiveness in combating the poverty all over the country.
\end{abstract}

Keywords: Poverty. Combating. Plan No Poverty Brazil.

Recebido em: 18/11/2014. Aceito em: 12/09/2014

"Doutoranda em Serviço Social pela Universidade Federal de Santa Catarina (UFSC). Mestre em Ciências Sociais Aplicadas pela UEPG; Especialista em Formação de Professores para a Docência no Ensino Superior Formada em Serviço Social pela Unicentro; Formada em Serviço Social também pela Unicentro e atualmente é Coordenadora do Curso de Serviço Social da Faculdade Guairacá em Guarapuava - PR; e-mail: pratesammc@gmail.com. 


\section{Introdução}

A pobreza é um fenômeno que salta aos olhos diariamente, mas é tão antigo na história quanto a humanidade, assim como antigas são as iniciativas para o seu controle. Ela não teve início com o sistema capitalista, porque nos outros sistemas, tais como a escravidão e o feudalismo também possuíam pessoas em situação de pobreza. O que se obteve a partir do capitalismo foi a acentuação desse fenômeno por conta da intensificação da exploração do trabalho. Com o acirramento da exploração da força de trabalho, bem como a crescente acumulação da riqueza produzida, o que sobrou foi o aumento gradativo das situações de pobreza em todos os países onde o sistema se alastrou. O fenômeno em questão tem faces particulares em cada realidade. Para uma pessoa estar em situação de pobreza no Brasil pode não significar a mesma coisa que estar na mesma condição num país desenvolvido (PEREIRA, 2006). De acordo com Yazbek (2012), a pobreza precisa ser vista de forma multidimensional e numa perspectiva de totalidade. Tal perspectiva é o viés adotado pelo Banco Mundial, de acordo com Siqueira (2012) e Stein (2006). Todavia, analisar o fenômeno através da totalidade remete à teoria social crítica de Marx, através da qual se compreende a pobreza como fruto das relações sociais desenvolvidas no e pelo conflito capital e trabalho (SIQUEIRA, 2012).

O século $X X$ trouxe profundas mudanças para o mundo do trabalho, com importante aprofundamento a partir da década de 70 , através das crises do sistema capitalista. As crises propiciaram transformações do mundo do trabalho com o acirramento da exploração da força de trabalho, da precarização e da fragilização dos vínculos (ANTUNES, 2000). Além disso, geraram a fetichização e a financeirização do sistema (IAMAMOTO, 2007) e, consequentemente, o empobrecimento da classe trabalhadora. Isso obrigou os governos e a classe dominante - representada pelos seus principais porta-vozes internacionais, como o Fundo Monetário Internacional (FMI), o Banco Mundial (BM) e a Organização Mundial do Comércio (OMC), os quais lamamoto (2007) chama de "A Santíssima Trindade" do capital a pensar em estratégias de enfrentamento da pobreza. Diante do exposto, o presente artigo tem como objetivo discutir o combate à pobreza no Brasil através do Plano Brasil Sem Miséria, que pretende tirar da extrema pobreza mais de 16 milhões de pessoas.

\section{A face da pobreza na América Latina}

As expressões da Questão Social ${ }^{1}$ estão presentes em todos os países, capitalistas ou não. Entretanto, a Questão Social se apresenta mais acentuada nos países periféricos dependentes, como os da América Latina e do Caribe, por conta da intensidade com que o capitalismo explora os trabalhadores. De acordo com Yazbek (2012), a pobreza é fruto das relações capitalistas de produção, que produzem e reproduzem as desigualdades sociais, com ênfase nos países periféricos dependentes. "É uma categoria multidimensional, e, portanto, não se caracteriza apenas pelo não acesso a bens, mas é categoria política que se traduz pela carência de direitos, de oportunidades, de informações, de possibilidades e de esperanças" (YAZBEK, 2012, p. 290).

O Panorama Social da América Latina, resenhado pelo Relatório da Cepal/Onu (2011), aponta que a pobreza tem diminuído após a crise financeira de 2009. De acordo com o documento, o PIB per capita cresceu $4,8 \%$, ao passo que a taxa de ocupação aumentou em 0,6 pontos percentuais. Apesar da crise, a taxa de desemprego urbano passou de $8,1 \%$ para $7,3 \%$.

Neste contexto, o índice de pobreza da região
situou-se em $31,4 \%$, incluindo $12,3 \%$ de pes-
soas em condições de pobreza extrema ou
indigência. Em termos absolutos estas cifras
equivalem a 177 milhões de pessoas pobres,
das quais 70 milhões são indigentes. Deste
modo, no ano 2010 seguiu-se avançando
em redução da pobreza, cuja taxa diminuiu
1,6 pontos percentuais em relação a 2009 ,
enquanto a indigência se reduziu 0,8 pontos
percentuais (CEPAL/ONU, 2011, p. 11).

\footnotetext{
1 “A questão social não é senão as expressões do processo de formação e desenvolvimento da classe operária e de seu ingresso no cenário político da sociedade, exigindo seu reconhecimento como classe por parte do empresariado e do Estado. É a manifestação no cotidiano da vida social, da contradição entre o proletariado e a burguesia, a qual passa a exigir outros tipos de intervenção, mais além da caridade e repressão" (IAMAMOTO, 1998, p. 77).
} 
É importante ressaltar que a família que tem um rendimento per capita menor que $\mathrm{R} \$$ 70,00 mensais é considerada como vivendo em extrema pobreza, que é a mesma coisa que pobreza absoluta ${ }^{2}$, diferente de pobreza relativa ${ }^{3}$. Desde 1990, quando os Estados e as Agências Internacionais começaram a se preocupar com o aumento da pobreza, ela totalizava $17 \%$ pontos percentuais e a indigência, 10,3\%. Em 1999, a pobreza chegou a 12,4 pontos percentuais, enquanto a indigência foi de $6,3 \%$. Segundo o mesmo Relatório, desde 2010 doze países da América Latina puderam diminuir significativamente seus percentuais de pobreza, sendo: "[...] Peru (-3,5 pontos), Equador (-3,0 pontos), Argentina (-2,7 pontos), Uruguai (-2,0 pontos) e Colômbia ( $-1,4$ pontos). Nestes países a variação das taxas de indigência também apresentou sinal negativo, com quedas entre 0,5 e 1,7 pontos percentuais" (CEPAL/ONU, 2011, p. 12).

O Programa das Nações Unidas para os Assentamentos Humanos (ONU-Habitat, 2012) elaborou um relatório sobre as cidades latino-americanas, no qual mostra que o Brasil é o quarto país mais desigual da América Latina em distribuição de renda, ficando atrás somente de Guatemala, Honduras e Colômbia. De acordo com esse documento, o país ainda perde para a maioria dos países vizinhos no que tange à pobreza. O relatório mostra ainda que pouco mais de $20 \%$ da população vive em situação de pobreza ou indigência, percentual maior do que no Uruguai, na Argentina, no Chile e no Peru. Costa Rica e Panamá também ficam à frente do Brasil com percentuais menores na taxa de pobreza urbana. Entretanto, o número de pessoas pobres e indigentes no país reduziu pela metade em duas décadas, sendo de $41 \%$ em 1990 para $22 \%$ da população em 2009. A Argentina e Uruguai também reduziram pela metade o número de pobres, que hoje gira em torno de $9 \%$ da população em ambos os países. Porém, foi o

\footnotetext{
2 "Está diretamente associada à ideia de sobrevivência física, à satisfação de mínimos sociais necessários à reprodução da vida com um mínimo de dignidades humana" (PEREIRA, 2006, p. 233).

3 "É a satisfação de necessidades em relação ao modo de vida de uma dada sociedade. Esta também vinculada à relação entre pobreza e distribuição das riquezas socialmente produzidas" (PEREIRA, 2006, p. 232).
}

Chile o grande campeão no combate à pobreza, com redução de $70 \%$, sendo de $39 \%$, em 1990 , para $12 \%$ em 2009 , referente ao percentual da população pobre no país.

No Brasil, a discussão sobre a necessidade de enfrentamento da pobreza começou a compor a agenda pública a partir da década de 1990. Essa necessidade foi sendo incorporada à medida que organismos internacionais começaram a pensar e a propor estratégias para seu enfrentamento. A maior contradição do Brasil é que ele não é um país pobre, mas um país de muitos pobres (PEREIRA, 2006), por conta da má distribuição da renda e da não distribuição do poder. Para a autora, $64 \%$ dos países e $77 \%$ da população do mundo possuem renda inferior à do Brasil, onde "[...] a renda média dos $10 \%$ mais ricos representa 28 vezes a renda média dos $40 \%$ mais pobres" (BARROS, HENRIQUES e MENDONÇA apud PEREIRA, 2006, p. 243). De acordo com esses autores, para tirar as pessoas da situação de indigência no país seria necessário apenas $2 \%$ da renda das famílias brasileiras, e para acabar com a pobreza apenas $8 \%$. Vale ressaltar que a forma adotada para medir a situação de indigência e pobreza é estatística. Todavia, a pobreza no Brasil não se explica por conta da falta de alimentos, pois o país é um dos maiores produtores; não explica pela falta de capacitação das pessoas em situação de pobreza, conforme configura o pensamento de Amartya Sen (2000), e tampouco pelo contingente populacional. Ao analisar a pobreza a partir da teoria marxista percebe-se que ela está relacionada à organização capitalista de produção (SOTO, 2003), onde se alimenta a relação antagônica entre duas classes - trabalhadora e burguesa - em que a última detém todos os meios de produção, força política e econômica para manter os trabalhadores dependentes da venda de sua única mercadoria: a força de trabalho.

De acordo com dados do Ministério do Desenvolvimento Social e Combate à Fome (MDS), atualmente se tem no país mais de 16 milhões de brasileiros com renda familiar per capita inferior a $R \$ 70,00$ mensais $^{4}$, os quais são foco dos Programas de Transferência

\footnotetext{
4 Dados disponíveis no site http://www.brasilsemmiseria.gov.br/ gestao-e-acompanhamento Acesso dia 15 de fevereiro de 2012
} 
Condicionada de Renda (PTCR). Um desses programas, o Programa Bolsa Família (PBF), criado em 2003, é atualmente o maior programa de transferência de renda do mundo e tem como proposta o enfrentamento da pobreza, buscando o seu alívio imediato.

Um estudo realizado pelo Instituto de Pesquisa Econômica Aplicada (IPEA) sobre a Pesquisa Nacional por Amostra de Domicílios de 2009, do Instituto Brasileiro de Geografia e Estatística (PNAD/IBGE), avalia a distribuição de renda no Brasil entre 1995 a 2009 e mostra que o país continua um país desigual, embora mostre certa queda da desigualdade na distribuição de riquezas. O IPEA (2010) aponta que a desigualdade continua caindo, mas em um ritmo um pouco mais lento. De acordo com o índice de Gini ${ }^{5}$, analisado neste estudo, "[...] o ritmo dessa queda se reduziu um pouco. De 2001 a 2008, a desigualdade medida pelo Coeficiente de Gini caiu em média 0,70 ponto de Gini (x100)2 ao ano. De 2005 a 2008, o ritmo foi um pouco mais forte e a desigualdade caiu 0,72 ponto de Gini (x100) ao ano. Já de 2008 a 2009, a desigualdade caiu menos: 0,54 ponto" (IPEA, 2010, p. 03).

Salienta-se que a pobreza é medida com base na renda per capita e o IPEA (2010) apresenta a proporção de pessoas em situação de pobreza, segundo três linhas diferentes, sendo: "[...] meio salário mínimo de 2009 per capita (uma linha relativamente alta), a linha de pobreza do Bolsa Família quando da criação do programa (R\$100 per capita em 2004) e a linha de pobreza extrema do Bolsa Família, também quando de sua criação ( $R$ \$ 50 per capita em 2004 - uma linha relativamente baixa) (IPEA, 2010, p. 12-13). Apesar da taxa de pobreza estar caindo, conforme mencionado acima, o Brasil continua sendo um país que tem uma taxa de pobreza alta, se comparado a outros países latinoamericanos. A face da pobreza é tendencialmente negra e feminina, conforme aponta o relatório da Cepal/Onu (2011). Isso mostra que o Brasil é um país desigual não

\footnotetext{
5 "O Índice de Gini, criado pelo matemático italiano Conrado Gini, é um instrumento para medir o grau de concentração de renda em determinado grupo. Ele aponta a diferença entre os rendimentos dos mais pobres e dos mais ricos. Numericamente, varia de zero a um (alguns apresentam de zero a cem). O valor zero representa a situação de igualdade, ou seja, todos têm a mesma renda. $O$ valor um (ou cem) está no extremo oposto, isto é, uma só pessoa detém toda a riqueza". Esse conteúdo está disponível em:
}

apenas na questão econômica, mas também em outras questões, como cultura e gênero.

\section{O debate sobre a política de enfrentamento da pobreza na América Latina}

Ivo (2006) problematiza o modelo de política social pensado na esfera governamental para o enfrentamento da pobreza nos países subdesenvolvidos da América Latina na era neoliberal. Nas décadas de 1970 e 1980 o tema da pobreza na América Latina foi tratado juntamente com as teorias de desenvolvimento no capitalismo periférico. Na década de 1990, sua retomada:

[...] emerge no curso de um processo de mudança mais recente, no qual distinguimos três movimentos e conjunturas distintas nas relações entre Estado e Sociedade, que conformam movimentos de hegemonia e contra hegemonia entre atores multilaterais e forças neoliberais com atores nacionais e locais, determinando limites e desafios ao Estado e à ação pública, especialmente quanto ao tratamento da questão social (IVO, 2006, p. 65-66).

O primeiro movimento aconteceu entre as décadas de 1970 e 1980 na luta pela democracia, empreendida pelos trabalhadores e suas diversas formas de expressão através dos movimentos sociais, especialmente na área urbana, pois a crise do capital acirrou ainda mais as expressões da pobreza entre os trabalhadores, uma vez que o ônus da crise recaiu sobre o trabalho. Como a Ditadura Militar encontrava-se em crise, acreditava-se que o momento era propício para a democratização do país. Isso favorecia a luta dos trabalhadores, mas também abria o país para o espraiar do capitalismo. Assim, trabalhadores e burgueses se uniram para empreender a luta pela democracia.

Em nível mundial, o neoliberalismo nasceu logo após a Segunda Guerra Mundial nos países onde o Capitalismo era forte, como na região da Europa e da América do Norte (ANDERSON, 1995). Para o autor, o ideário neoliberal foi uma forma de reagir frente à atuação do Estado no enfretamento das demandas originárias dos trabalhadores. O neoliberalismo é uma ideologia que possui a mesma vertente liberal e que tem suas raízes plantadas no liberalismo clássico, só que em outro formato. Agora, prega-se o 
intervencionismo do Estado, mas na economia. Isso era diferente no liberalismo clássico em que o Estado era completamente afastado, tanto do social, quanto do econômico.

Nem bem foi instituído um Estado que poderia ser chamado de Democrático de Direito, e já vieram as reformas na década de 90 que favoreceram a ascensão da proposta neoliberal pactuada no Consenso de Washington em 1989 no âmbito mundial, onde os sete países mais ricos do mundo (Grupo dos 7 ou G7), a partir do final da década de 80 , passaram a deliberar como as demais nações deviam ajustar-se à nova ordem mundial. Apoiadas nas deliberações do Consenso ficaram estruturadas as bases da nova política econômica e social, que passaram a impor uma ideologia difundida mundialmente. As propostas adotadas a partir do Consenso estão relacionadas à "[...] estatização econômica (combate à inflação); realização das reformas estruturais (privatização, desregulamentação de mercados, liberação financeira e comercial); retomada dos investimentos estrangeiros para incrementar o desenvolvimento" (SILVA, 2007, p. 59).

A segunda etapa desse movimento citado por Ivo (2006) aconteceu no início da década de 1990, quando o ideário neoliberal chegou ao Brasil. O Brasil tinha aprovado recentemente sua Constituição chamada Cidadã e as receitas neoliberais entraram no país como uma avalanche de desmonte de direitos sociais conquistados pela classe trabalhadora nas décadas anteriores. A terceira fase desse movimento, segundo Ivo (2006), teve início no final da década de 1990 quando se percebeu os limites perversos da avalanche neoliberal de desmonte de direitos, que, associada à crise do capital onerando o trabalho, aumentou as expressões da pobreza no país. De acordo com Stein (2006), é nesse mesmo período que o Banco Mundial assume com intensidade as estratégias de combate à pobreza. Esse contexto passou a contar mais com os monopólios manifestados na concentração de capitais, fusão de empresas, onde prevalece sempre o mais forte, econômica, politicamente e com maior capacidade de se manter no mercado. $E$, além disso, passou a contar também com a política de contratação de empregos e suas expressões de contratações precárias e instáveis.
Do ponto de vista governamental, intervir sobre a pobreza significa desenvolver uma inteligência estratégica para que a política social atue nos limites do ajuste econômico, e contrapondo as políticas de assistência política social prioritária, de natureza focalizada - à de proteção, sujeita a uma reforma da Previdência, de resultados incertos, que transfere grande parte dessa função pública ao setor privado (IVO, 206, p. 67).

A forma de intervenção encontrada através de política social no enfrentamento à pobreza, tanto no Brasil como em outros países, foi a focalização, que tinha como objetivo "[...] reduzir os efeitos adversos dos ajustes estruturais e da reestruturação produtiva, institucionalizando-se à margem do campo da proteção social" (IVO, 2006, p. 67). A focalização inaugurou um novo modelo de política social desenvolvida pelo Estado no intuito de "[...] fortalecer a capacidade dos pobres para lutarem contra a pobreza" (IVO, 2006, p. 68).

Stein (2006) fala que a proposta do Banco Mundial continha três elementos básicos, são eles: "[...] estratégias de manejo de risco (prevenção, mitigação e superação de eventos negativos); sistemas de manejo de riscos (informais, de mercado e públicas); e atores no manejo de riscos (indivíduos, famílias, comunidades e ONGs, instituições de mercado, governos, organizações internacionais e a comunidade em geral)" (STEIN, 2006, p. 106). Tanto Ivo (2006) quanto Stein (2006) concordam que essas mudanças foram orientadas por alguns paradigmas próprios do ideário neoliberal para pensar e operar a política social. E Ivo (2006) mostra o desdobramento desses paradigmas na operacionalização da política social, como se pode ver a seguir. 
QUADRO 1 - Paradigmas neoliberal presentes na operacionalização da política social

\begin{tabular}{|c|l|}
\hline \multicolumn{2}{|c|}{ PARADIGMAS } \\
$\begin{array}{c}\text { Natureza } \\
\text { estratégica }\end{array}$ & $\begin{array}{l}\text { Operar a política social por meio da focalização, identificando e definindo } \\
\text { bem o público-alvo de forma fragmentada, com ênfase na diferenciação } \\
\text { do acesso aos serviços, focando nas demandas categoriais. }\end{array}$ \\
\hline Caráter societal & $\begin{array}{l}\text { Redefinir as responsabilidades do Estado e da Sociedade Civil, formando } \\
\text { parcerias com o objetivo de atacar os focos de pobreza na realidade. }\end{array}$ \\
\hline $\begin{array}{c}\text { Racionalidade } \\
\text { econômica }\end{array}$ & $\begin{array}{l}\text { Transferir determinado valor monetário às famílias em situação de } \\
\text { pobreza, com o objetivo de estimular a sua inserção no mercado como } \\
\text { consumidores. }\end{array}$ \\
\hline
\end{tabular}

Fonte: IVO, 2006, p. 68.

Org.: a autora.

Com isso o que se tem na América Latina e no Brasil é uma reconversão da Questão Social a uma dimensão política de proteção. Deixa-se de pensar a proteção social como uma expressão de justiça social para se pensar nos efeitos da Questão Social enquanto tal, ou seja, "[...] em termos de mediadas mitigadoras setorizadas e focalizadas da pobreza, no âmbito das políticas sociais" (IVO, 2006, p. 69). Não se analisa a origem de suas expressões, mas foca-se nos seus efeitos imediatos para uma intervenção também imediata. Portanto, o resultado dessas intervenções também não passa de ações passageiras.

Outro aspecto pertinente nesse processo é que se passou a olhar a pessoa em situação de pobreza como responsável pela sua condição. Por isso, as políticas sociais estão pautadas em vieses que buscam "[...] o fortalecimento da capacidade dos pobres para lutarem contra a pobreza, como sujeitos desse processo, o que significa que o encaminhamento da erradicação da pobreza considera as variáveis políticas e societais no controle e implantação dessas políticas" (IVO, 2006, p. 69). Para a autora, essa dimensão pauta-se numa cultura política que desenvolveu relações clientelistas e corporativistas, tornando a pessoa em tal situação um cliente que lhe deve favores. Logo, desvia-se o foco da origem da pobreza, colocando-o apenas nos seus efeitos imediatos, e, além disso, responsabilizando a principal vítima: a pessoa que vivem em situação de pobreza. Nesse sentido, "[...] desloca-se o centro da política social de uma dimensão de distribuição da riqueza para o tratamento compensatório da assistência a partir dos efeitos dessa distribuição restritiva: a pobreza, a miséria, aprofundando um conflito redistributivo de base [...]" (IVO, 2006, p. 69).

De acordo com a autora, o modelo de política social para o enfrentamento à pobreza, mantém inalterada as condições de distribuição de riqueza nos países, pois "[...] o diagnóstico da erradicação da pobreza desvincula os pobres do sistema de proteção social, passando a assistência a constituir-se em um atributo individual para aqueles que 'moralmente' têm direito ou potencialmente para se desenvolverem" (IVO, 2006 , p. 69). Nesse sentido, continua-se com a desigualdade social sem alterações substancias, uma vez que as proposituras de enfrentamento da pobreza desconsideram a sua origem nas relações capitalistas de produção.

\section{As variantes na concepção do conceito de pobreza}

Normalmente, o conceito que se tem a respeito de qualquer fenômeno leva os sujeitos a agirem de acordo com eles. O enfrentamento efetivo da pobreza não aconteceu ainda porque se tem vários tipos de abordagens do conceito de pobreza, o que implica na forma como se pensa e se operacionaliza o seu enfrentamento. Ivo (2006) mostra que há consenso quanto à necessidade de se enfrentar esse fenômeno na contemporaneidade; no entanto, não há consenso quanto à sua concepção, e pouco há sobre o entendimento de que a pobreza é apenas uma expressão da desigualdade social e que esta é fruto do sistema capitalista de produção.

Uma concepção vigente sobre a pobreza é 'o controle dos pobres: visão repressiva da questão da pobreza’. Nesse ínterim, "[...] 
a primeira ideia amplamente difundida sobre a pobreza é a afirmação de que seu aumento e sua agudização induziriam a um descontentamento crescente das populações de pobres, a uma potencialização dos conflitos e ao aumento da violência" (IVO, 2006, p. 75). Por isso, sustenta também Stein (2006), a perspectiva que orienta a configuração das políticas de combate à pobreza vem de Amartya Sen ${ }^{6}$, segundo o qual "[...] a centralidade mais no indivíduo do que no coletivo, mais na sociedade do que no Estado, mais na liberdade do que na igualdade" (STEIN, 2006 , p. 91). É comum atribuir às pessoas em situação de pobreza a violência nas grandes cidades, a delinquência urbana, a insegurança social no convívio nos centros urbanos. Esse pensamento justifica a necessidade que se tem de controlar os pobres e enfrentar a pobreza, não como uma expressão de injustiça social, mas como uma expressão de incômodo à classe dominante que se sente insegura quanto à tomada de seus bens. "A gravidade desses fatos legitimaria uma intervenção pública consistente no controle das áreas marginais e da pobreza e no desenvolvimento de políticas voltadas para a segurança pública dos cidadãos" (IVO, 2006, p. 76). No entanto, como se sabe, não se pode atribuir às pessoas em situação de pobreza a responsabilização pela violência, pelas drogas e pela criminalidade, pois a classe média e a burguesia também participam efetivamente desses fenômenos sociais. E, "Por outro lado, a análise exclusivamente centrada sobre a "violência da pobreza' não só pode discriminar populações empobrecidas, como incorrer no risco de reconverter políticas sociais em políticas repressivas de 'controle' dos pobres" (IVO, 2006, p. 76).

Para Stein (2006), ainda falando da perspectiva de combate à pobreza por parte do Banco

\footnotetext{
6 "A perspectiva da organização política dos pobres origina-se de uma visão de desenvolvimento social e humano construída por Amartya Sen, Prêmio Nobel de Economia de 1998. Essa abordagem procura transformar os pobres de um "sujeito passivo" em um "sujeito ativo", beneficiário de planos sociais e protagonista da mudança social, envolvendo o desenvolvimento de capacidades estratégicas. Ela orientou os relatórios do PNUD quanto ao desenvolvimento social e humano e à necessidade de democratização do acesso a capacidades (educação, saúde, poder, etc.) que permitam aos pobres se transformarem em sujeitos de sua luta. Esta retórica tem sido reapropriada segundo diferentes atores políticos e sociais em quadros políticos e ideológicos distintos, que nem sempre correspondem à sua concepção original ou que assimilam apenas parcialmente essa tese" (IVO, 2006, p. 77).
}

Mundial, percebe-se que o crescimento das desigualdades expressas no crescimento da pobreza incomoda os capitalistas. Isso fica claro no discurso de Robert MacNamara, presidente do Banco Mundial em 1972:

Quando os privilegiados são poucos, e os desesperadamente pobres são muitos e quando a diferença entre ambos os grupos se aprofunda em vez de diminuir, só é questão de tempo até que seja preciso escolher entre os custos políticos de uma reforma e os riscos políticos de uma rebelião. Por esse motivo, a aplicação de políticas especificamente encaminhadas para reduzir a miséria dos $40 \%$ mais pobres da população dos países em desenvolvimento, é aconselhável não somente como questão de princípio, mas também de prudência ${ }^{7}$. A justiça social não é simplesmente uma obrigação moral, mas também um imperativo político (McNAMARA apud STEIN, 2006, p. 97-98).

Como se pode perceber, o combate à pobreza não passa por uma perspectiva de direitos humanos, igualdade e justiça social, mas por uma questão política. Talvez fique à margem do esquecimento que a pobreza é a maior violência que o sistema capitalista pode impor à classe trabalhadora, obrigando-a a produzir todos os bens de consumo, mas impedindo que ela tenha acesso a esses mesmos bens para satisfação plena de suas necessidades humanas e sociais. Essa perspectiva é clara quando os trabalhadores, por meio de lutas e reivindicações, conquistam direitos no e pelo Estado. As pequenas concessões feitas nas e pelas políticas públicas nem sempre significam a efetividade dos direitos apenas, mas o reflexo do medo que a burguesia estatal e mercadológica tem dos trabalhadores organizados.

De acordo com Ivo (2006), outra concepção vigente é a 'refilantropização da pobreza'. A criminalização da pobreza, a repressão e o controle das pessoas em situação de pobreza não é fenômeno atual da sociedade, pois nos séculos passados, quando não havia uma concepção crítica sobre a origem da pobreza, essas populações eram tidas como vagabundas quando não conseguiam inserir-se no mercado formal de

\footnotetext{
${ }^{7}$ Destaque da autora.
} 
trabalho (YAZBEK, 2003) e (ALAYÕN, 1992). Por um lado, percebe-se a necessidade de enfrentar o fenômeno da pobreza no país, mas por outro:

[...] firma-se cada vez mais o compromisso de toda a sociedade no enfrentamento dessa questão, através do apoio de uma ampla rede de sociabilidade comunitária, a partir de práticas solidárias - algumas de caráter filantrópico -, muitas vezes alternativas à ausência do Estado. Ou seja, as mudanças e diagnósticos críticos quanto à ação restritiva do Estado no âmbito das políticas sociais, assim como o capital social preexistente, de algumas ONGs e entidades filantrópicas, têm solidificado o caráter emergencial e estratégico da ação humanitária em favor das camadas mais pobres da sociedade (IVO, 2006, p. 76).

Vive-se num país democrático, onde se prima pelos princípios de uma nova relação entre Estado e Sociedade Civil, em que ambos são parceiros na operacionalização de Políticas Públicas (NOGUEIRA, 2005). No entanto, nesse mesmo Estado estão presentes os ideários neoliberais que incentivam uma participação maior da Sociedade Civil para que o Estado repasse suas responsabilidades para ela, perdendo a sua primazia na condução das políticas. Logicamente, não é isso que se mostra nos discursos, porém, é exatamente isso que se traduz na prática cotidiana dessa relação. $E$ isso é um dos pilares fundamentais do processo de reforma do Estado empreendido a partir da década de 1990 (BRASIL, 1995).

Outra concepção de pobreza, ainda segundo Ivo (2006), é a percepção dos pobres como sujeitos potencialmente mobilizadores. Reconhecer os pobres como sujeitos é um passo positivo, mas o problema é atribuir a eles a responsabilidade por sair da condição de pobreza que o sistema capitalista lhes impõe.

Isso supõe entender que a questão da pobreza envolve, também, o desenvolvimento de capacidades preexistentes dos próprios pobres no provimento das condições de superação da pobreza. Essa percepção, mais recente, implica a compreensão de que as questões do desenvolvimento supõem sujeitos participativos e engajados, ou seja, o desenvolvimento do senso cívico (IVO, 2006, p. 77).
Essa perspectiva foi desenvolvida através das teorias de Amarty Sen, como também mostra Stein (2006). Essa percepção também se faz presente na concepção das políticas sociais toda vez que, em sua operacionalização, se tem como estratégia o desenvolvimento de capacidades. Pode-se tomar como exemplo a Política de Assistência Social (PNAS, 2004), que trabalha com a perspectiva do desenvolvimento de capacidades dos sujeitos, buscando inseri-lo no mercado de trabalho. Para a perspectiva da política neoliberal, "[...] mobilizar o potencial dos pobres implica aproveitar a capacidade existente nas comunidades, canalizando-a para resolver, a um só tempo, os problemas materiais da pobreza, da participação e da integração social através de sua inserção no mercado" (IVO, 2006, p. 77). Segundo a autora, a organização dos pobres para o enfrentamento das suas demandas possuem dois vieses, um positivo e outro negativo, sendo que:

A perspectiva negativa entende a pobreza como fenômeno localizado e residual, incompatível com o progresso da sociedade industrial, podendo avançar em políticas repressivas ou tutelares de gestão da miséria e da assistência. Do ponto de vista positivo, implica reconverter o potencial combativo e de resistência dos pobres em "ativos" (em termos de bens de base disponíveis) para resolver a sua própria condição de vulnerabilidade social (IVO, 2006, p. 77).

Na realidade, o fator positivo, apontado pela autora, apenas enfoca a necessidade de integrar a pessoa em situação de pobreza, preparando-a para o mercado de trabalho a fim de que ela se torne uma cidadã consumidora integrada ao mercado. A perspectiva do Banco Mundial comunga do viés neoliberal que busca tornar os pobres ativos e ativar a sua resistência. "Neste sentido, o Banco reconhece que as populações vulneráveis têm a propriedade de 'ativos' sociais, econômicos e culturais que poderiam e deveriam ser mobilizados no provimento de soluções da pobreza" (IVO, 2006, p. 78). Essa perspectiva dá conta de entender que as pessoas que vivem nessa condição são passivas e, por isso, a sua resistência precisa ser ativada.

Existe, também, nessa concepção de pobreza um 'discurso afirmativo da pobreza no 
processo de formação do sujeito popular'. O Estado apresenta certa preocupação com gasto com política social que possa satisfazer as necessidades básicas do sujeito; entretanto, requer, também, que a pessoa em condição de pobreza possa ser organizada e autônoma na gestão de sua própria vida, e ainda que seja:

[...] sujeito capaz, na arena social, de desenvolver processos autogestivos orientados para a satisfação das necessidades básicas, que, inclusive, pode se encarregar da gestão global do habitat através de práticas autônomas da base popular democraticamente organizada; e, no plano político, capaz de reivindicar e impulsionar, no âmbito da cidadania, o exercício pleno dos direitos cidadãos e a participação na formulação e orientação das políticas públicas (IVO, 2006, p. 79).

O problema não está em propor políticas que contribuam para o desenvolvimento do potencial das pessoas em situação de pobreza, mas justamente no fator individualizante do problema, que é social, econômico e político, com vínculo intrínseco com a organização econômica mundial. O discurso não dito afirma a essas pessoas que elas são responsáveis pela sua situação e que qualquer melhora ou piora depende delas e não do Estado que "Ihe oferece todas as oportunidades".

Ivo (2006) afirma que existem algumas concepções críticas sobre o crescimento da pobreza. Algumas acreditam-na como injustiça social na forma de dívida histórica construída por um processo de exclusão e desigualdade social que impediu muitos sujeitos de participarem dos benefícios da modernidade (IVO, 2006). Outro aspecto que ela aponta é que a pobreza tem a função de reproduzir a dominação política, quando possibilita aos países a formação do clientelismo, do patrimonialismo e do assistencialismo que facilita a repressão, a submissão e a dependência dos pobres aos agentes políticos. E, ainda de acordo com Ivo (2006), outros autores atribuem a pobreza à crise do fordismo e seus efeitos sobre a classe trabalhadora.

Finalmente, encontram-se os argumentos mais políticos que apontam para a manipulação estratégica e autoritária da pobreza, como condição de construção da legitimidade e do consentimento de grupos hegemônicos locais, através de estímulos da televisão e da mídia para a recriação de uma base de legitimidade de caráter personalista e, portanto, antidemocrático (IVO, 2006, p. 80).

Ainda dentro da perspectiva dos pobres como sujeitos mobilizadores encontra-se outro viés das agências internacionais e governos. Essas agências são: o Banco Interamericano de Desenvolvimento (BID), a Comissão Econômica para a América Latina e o Caribe (CEPAL) e o Programa das Nações Unidas para o Desenvolvimento (PNUD). "A visão tecnocrático progressista atribui grande importância à superação da pobreza como estratégia de desenvolvimento e postula a necessidade de apoio público à economia popular" (IVO, 2006, p. 81). A autora critica essa concepção do fenômeno, pois se centra mais nos efeitos produzidos por ele do que nas suas causas.

Como se pode perceber, existem várias dimensões na concepção teórica de pobreza; no entanto, a pobreza é pouco analisada sob viés marxista. Essa é a tarefa de Soto (2003), a qual traz em seu texto a discussão sobre o conceito de pobreza a partir da perspectiva teórica de Marx. Ela parte de quatro pressupostos para a compreensão desse fenômeno. Primeiro, as teorias dominantes entendem as relações sociais burguesas como sendo eternas e imutáveis. Isso faz com que haja certa negação do movimento histórico da classe trabalhadora na luta pela conquista de seus direitos. Segundo, é preciso ter claro que as relações sociais são produtos da humanidade e, nesse sentido, "[...] La pobreza se compreende em La sociedad capitalista, entendiendo el desarrollo de las fuerzas producivas y las relaciones sociales específicas que engendra este desarrollo; $y$ desmisfiticando lãs ideias y categorías associadas al mismo otorgándole su caráter histórico concreto" (SOTO, 2003, p. 08-09). Terceiro, é necessário entender que as relações sociais formam um todo, ou seja, elas formam uma totalidade concreta em movimento. "Compreender La pobreza exige conocer las condiciones materiais de existência de lós hombres, definiendo a los mismos no como espectadores de su história sino como 'autores y actores a um tiempo mismo de su próprio drama'” (SOTO, 2003, p. 09). O quarto pressuposto que a autora apresenta afirma que compreender a pobreza 
a partir de relações sociais imutáveis e eternas impõe-se como obstáculo ao seu enfrentamento, pois se percebe como impossível de ser combatida, uma vez que ela é enquadrada numa concepção hegemônica. "Es obvio que esta posición objetiva conservadora de la burguesia, niega el antagonismo y las contradicciones inherentes a las condiciones modernas de producción" (SOTO, 2003 , p. 10). No entanto, a partir de um viés marxista só se explica a pobreza caso haja a compreensão do desenvolvimento antagônico da sociedade capitalista. São essas relações que geram a pobreza e a miséria para os trabalhadores, que produzem toda a riqueza, mas não usufruem do produto de seu trabalho. Ao contrário do que pregam as teorias dominantes, a pobreza "[...] se define como una categoria compleja, histórica y mutable. Es decir, una categoria relacional que solo se explica entendiendo el movimiento de la totalidad social" (SOTO, 2003, p. 10).

Para Soto (2003), a pobreza desempenha um duplo papel: ao mesmo tempo em que ela é fruto e também condição para a acumulação capitalista. Fruto porque nasce a partir do processo de acúmulo de riquezas por parte da classe dominante. E condição porque para haver acúmulo precisa se tirar de outros, nesse caso dos produtores da riqueza: dos trabalhadores, através da extração da mais-valia.

Junto con el aumento del capital, aumenta también la masa de 'pobres trabajadores', es decir, de obreros asalariados, cuja fuerza de trabajo se matemorfosea en cresciente fuerza de exploración a benefício del cresciente capital, ló que lós fuerza para sobrevivir y reproducirse a eternizar su supeditación al próprio pruducto de su trabajo, personificando en el capitalista (SOTO, 2003, p. 11).

A mercadoria que o trabalhador tem para ser vendida é somente a sua força de trabalho, a qual entrega antecipadamente por um salário para satisfação de suas necessidades e de sua família. De acordo com autora, a pobreza do trabalhador é condição necessária para a sustentação do regime capitalista, onde a miséria é a condição de existência dele. "De este mecanismo se desprende que a medida que se acumula capital, tiene 'necessariamente'que deteriorarse, que empobrecerse la situación del trabajador (independientemente de su retribución, ya sea ésta alta o baja)" (SOTO, 2003, p. 12). Os mecanismos de produção e acumulação capitalista dão conta de adaptar o número de trabalhadores necessários à manutenção do sistema funcionando lucrativamente. Os trabalhadores que sobram ficam na miséria, esperando uma oportunidade para vender a sua força de trabalho no mercado, mas isso quando o sistema quiser. A lógica da lei de acumulação capitalista "[...] determina una acumulación de miseria, de tormentos de trabajo, de escravitud, de despotismo, de ignorância y degradación moral, de barbarización social" (SOTO, 2003, p. 13). Isso afeta as condições materiais de existência e de reprodução dos trabalhadores, tanto aqueles que estão vendendo a sua força de trabalho, quanto os que formam o Exército Industrial de Reserva. Para enfrentar essa situação criada pelo sistema capitalista é que os Estados implementam políticas públicas das mais variadas formas. Algumas para atender aos trabalhadores ativos e outras para atender àqueles que se encontram em situação de pobreza e extrema pobreza. Sabe-se que o viés que alimenta a perspectiva das políticas sociais no Brasil não advém da teoria marxista, mas do viés imposto pelas agências internacionais, como visto acima. Todavia, a partir do que foi apresentado até aqui é que analisar-se-á uma dessas estratégias governamentais: o Plano Brasil Sem Miséria, que auspiciava combater a extrema pobreza no Brasil até 2014.

\section{O enfrentamento da pobreza através do Plano Brasil sem Miséria}

Com o sonho de acabar com a miséria extrema no Brasil foi criado o Plano Brasil Sem Miséria, que teve seu lançamento em 2011. Ele foi instituído pelo Decreto $N^{\circ} 7.492$, de 02 de junho de 2011, no qual consta que tem a finalidade "[...] de superar a situação de extrema pobreza da população em todo o território nacional, por meio da integração e articulação de políticas, programas e ações" (BRASIL, 2011, Art. 01). De acordo com o referido decreto, esse plano é destinado aos brasileiros que vivem em situação de extrema pobreza, ou seja, aquelas pessoas que vivem com renda familiar per capita de até 
$\mathrm{R} \$ 70,00$ por mês ${ }^{8}$. Com a execução desse plano, o governo federal pretendia superar a extrema pobreza no Brasil até 2014. As diretrizes do Plano Brasil Sem Miséria são:

I - garantia dos direitos sociais; II - garantia de acesso aos serviços públicos e a oportunidades de ocupação e renda; III - articulação de ações de garantia de renda com ações voltadas à melhoria das condições de vida da população extremamente pobre, de forma a considerar a multidimensionalidade da situação de pobreza; e IV - atuação transparente, democrática e integrada dos órgãos da administração pública federal com os governos estaduais, distrital e municipais e com a sociedade (BRASIL, 2011, Art. 03).

Ressalta-se que o governo entende que acabar com a miséria é fazer com que a renda familiar per capita ultrapasse os R\$ 70,00 (FALCÃO e COSTA, 2014). Isso significa que se uma família puder obter $R \$ 70,02$, por exemplo, ela já saiu da linha de extrema pobreza, ou seja, não faz parte mais das estatísticas brasileiras como extrema pobreza. Logo, é preciso cuidado para analisar: até que ponto o país acabaria com a extrema pobreza, uma vez que a medida desta é apenas via dados estatísticos? A intenção governamental se mostra nos seguintes objetivos do plano:

I - elevar a renda familiar per capita da população em situação de extrema pobreza; II - ampliar o acesso da população em situação de extrema pobreza aos serviços públicos; e III - propiciar o acesso da população em situação de extrema pobreza a oportunidades de ocupação e renda, por meio de ações de inclusão produtiva (BRASIL, 2011, Art. 04).

Para a identificação do denominado público-alvo do Plano Brasil Sem Miséria, bem como para o planejamento das ações, são utilizados os dados dos cidadãos registrados no Cadastro Único para Programas Sociais do Governo Federal.

A primeira ação para identificar o público-alvo é a Busca Ativa. Através dela os municípios identificam as famílias que vivem em situação de extrema pobreza, ou seja, com uma renda de até

\footnotetext{
${ }^{8}$ É importante frisar que em 2014 era considerada extremamente pobre a pessoa que vivesse com renda familiar per capita de até $\mathrm{R} \$ 77,00$ e em 2016 esse valor subiu para $\mathrm{R} \$ 85,00$
}

$\mathrm{R} \$ 70,00$ per capita. Segundo Campello e Mello (2014), dados do Censo de 2010 afirmam que se tem no país 16,2 milhões de pessoas vivendo na extrema pobreza. A estratégia é que os municípios busquem essas famílias, as quais não são visualizadas pelo poder público e contam com nenhuma proteção social.

Fazer a Busca Ativa não significa meramente incluir famílias pobres em um sistema informatizado. Significa levar uma série de serviços públicos e oportunidades para a população mais pobre do país, a partir de seu ingresso no Cadastro Único. É por isso que a Busca Ativa orienta todas as ações do Brasil Sem Miséria e que o Cadastro é fundamental no plano (MDS, 2013a, p. 21)

São vários os motivos que fazem com que as famílias em situação de pobreza e, em especial em extrema pobreza, não estejam acessando os serviços públicos aos quais têm direito. Isso acontece por conta da árdua tarefa de alcançar aqueles que estão fora da rede de proteção social:

O desafio é alcançar aqueles que não acessam os serviços públicos e vivem fora de qualquer rede de proteção social. A ausência de documentação civil migrações constantes, residência em territórios com conflitos, pertencimento a populações tradicionais que habitam áreas isoladas ou distantes, pertencimento a segmentos socialmente excluídos, desconhecimento de seus direitos, entre outros, dificultam o acesso dessas famílias aos programas sociais municipais, estaduais e federais (BRASIL, 2014 apud CABRAL, ONCALA, GAIVIZZO e APOLONI, 2014, p. 502-503).

Através da Busca Ativa equipes dos CRAS identificam as famílias, cadastram-nas no Cadastro Único do Sistema Único de Assistência Social (CADÚNICO) e mantêm atualizados os seus dados para que estas possam acessar os serviços públicos, sendo inseridas na rede de proteção social. "Considera-se rede socioassistencial o conjunto integrado da oferta de serviços, programas, projetos e benefícios de assistência social mediante articulação entre todas as unidades de provisão do SUAS (BRASIL, 2012, Art 9)". Integrando a rede socioassistencial, os demais programas, projetos e serviços públicos vêm contribuir para proporcionar às famílias 
oportunidades de inclusão produtiva, a garantia de renda e os serviços, conforme previsto pelo Plano Brasil Sem Miséria.
A ação de Busca Ativa do Plano Brasil Sem Miséria é desenvolvida em três momentos específicos, conforme se pode observar no Quadro Il a seguir:

QUADRO 2 - Etapas da Busca Ativa do Plano Brasil Sem Miséria

\begin{tabular}{|c|c|c|}
\hline ETAPA & ESTRATÉGIA & AÇÕES \\
\hline $1^{a}$ & $\begin{array}{l}\text { Inclusão no Cadastro } \\
\text { Único do SUAS }\end{array}$ & $\begin{array}{l}\text { Localizar as famílias extremamente pobres, incluí-las no Cadastro } \\
\text { Único (CadÚnico) e manter suas informações sempre atualizadas; }\end{array}$ \\
\hline $2^{\mathrm{a}}$ & Acesso aos Benefícios & $\begin{array}{c}\text { Incluir no Programa Bolsa Família, no Programa Bolsa Verde }{ }^{9} \text {, no } \\
\text { Fomento a Atividades Produtivas, no Programa de Erradicação do } \\
\text { Trabalho Infantil e no Benefício de Prestação Continuada todas as } \\
\text { famílias que atendam aos critérios de elegibilidade; }\end{array}$ \\
\hline $3^{a}$ & Acesso aos Serviços & $\begin{array}{l}\text { Assegurar que as famílias extremamente pobres tenham acesso aos } \\
\text { serviços sociais básicos de saúde, saneamento, educação, assistência } \\
\text { social, trabalho e segurança alimentar e nutricional, entre outros. }\end{array}$ \\
\hline
\end{tabular}

Fonte: Site http://mds.gov.br/assuntos/brasil-sem-miseria/busca-ativa. Acesso dia 18 de agosto de 2016.

Org.: a autora.

Essas ações são desenvolvidas pelo MDS e mais 22 ministérios, em parceria com os estados e municípios. São ações articuladas do poder público como um todo, que envolvem todos os poderes, a fim de alcançar a meta de acabar com a extrema pobreza no país. Entre as ações desenvolvidas estão:

[...] a realização de mutirões, campanhas, palestras e atividades socioeducativas; o cruzamento de bases de dados; a promoção de visitas domiciliares dos agentes de assistência técnica do Ministério de Desenvolvimento Agrário, dos técnicos do INCRA, dos agentes de saúde do Ministério da Saúde, dos agentes ambientais do Ministério do Meio Ambiente, entre outros; a realização de processos de qualificação dos gestores públicos dos três

\footnotetext{
9 "O Programa Bolsa Verde faz parte do Plano Brasil sem Miséria e seu nome oficial é Programa de Apoio à Conservação Ambiental. O Programa é coordenado pelo Ministério do Meio Ambiente (MMA) e possui vários parceiros. Os objetivos do Programa são: incentivar a conservação dos ecossistemas, entendida como sua manutenção e uso sustentável; promover a cidadania; melhorar as condições de vida e elevar a renda da população beneficiária; e incentivar a participação de seus beneficiários em ações de capacitação ambiental, social, educacional, técnica e profissional". Como forma de incentivo à participação das famílias nesse programa, ele repassa a cada três meses um valor de $R \$ 300,00$, por meio do Cartão do Programa Bolsa Família, com duração de dois anos. Conteúdo disponível em: http://mds.gov.br/falemds/ perguntas-frequentes/bolsa-familia/bolsa-verde/beneficiarios/ bolsa-verde, Acesso dia 02 de maio de 2013.
}

níveis de governo para o atendimento à população extremamente pobre (MDS, s/d $\left.{ }^{10}\right)$.

A partir dos objetivos propostos, o Plano está estruturado em três eixos de atuação: Garantia de Renda, Acesso aos Serviços Públicos e Inclusão Produtiva (urbana e rural). O primeiro eixo é a Garantia de Renda às famílias em situação de pobreza, especialmente àquelas que têm crianças de 0 a 6 anos de idade. Para esse público o governo ampliou a quantidade de benefícios variáveis (de três para cinco). Segundo o MDS (2013b), essa medida impacta sobre a condição de pobreza da família que tem mais de três crianças e adolescentes com idade de 0 a 15 anos. Assim, o "[...] aumento do limite de Benefícios Variáveis por família levou ao pagamento de 1,3 milhão de novos Benefícios Variáveis relativos a crianças de todo o País no mês de setembro, quando foi implementado" (MDS, 2013b, s/p). Os benefícios variáveis também são pagos para famílias que têm bebês de 0 a 6 meses, pois é uma fase fundamental de seu desenvolvimento e precisa ter boa nutrição. Esse benefício é conhecido como "benefício variável nutriz". De acordo com o MDS (2013b, s/p), em novembro de 2011 foram pagos 69.059 benefícios nutriz. Em dezembro do mesmo ano, o governo lançou

\footnotetext{
10 Disponível em http://mds.gov.br/assuntos/brasil-sem-miseria/ busca-ativa . Acesso em: 18 ago. 2016.
} 
um benefício variável destinado à proteção das mulheres grávidas, o qual dá sequência ao benefício nutriz quando o bebê nasce. Para a grávida são pagos nove parcelas de $R \$ 32,00$, seguindo o pagamento quando nasce a criança por mais seis parcelas do mesmo valor.

A medida representa um estímulo à realização dos exames pré-natal, e também conta no limite de cinco Benefícios Variáveis por família. Sua implantação só foi possível graças ao aperfeiçoamento do sistema de gestão do MDS e à sua integração com o do Ministério da Saúde (MDS, 2013b).

Através disso o governo reconhece que a gestante e seu bebê, durante o período de gestação e lactação, estão vivendo um momento especial e, por isso, precisam de boa nutrição e saúde. A estimativa do governo era que em 2013 aproximadamente três milhões de pessoas (780 mil famílias) ultrapassassem a linha da extrema pobreza (cf. MDS, 2013b, s/p), ou seja, elas teriam renda per capita acima de $\mathrm{R} \$ 70,00$ mensais. Como se pode notar, o aumento da renda per capita advém dos benefícios e não de alguma oportunidade através do trabalho.

O segundo eixo do plano é o Acesso aos Serviços Públicos, através das políticas como Assistência Social, Saúde, Educação,
Segurança Alimentar, Habitação, combate ao Trabalho Infantil, acesso à luz, provimento de sua documentação e apoio à população que se encontra em situação de rua (MDS, 2013b, s/p). A expansão desses serviços devem contar com a qualidade no atendimento e serviços disponíveis suficientes para atender todas as demandas. Faz parte também desse acesso as vagas nas creches, escolas em tempo integral e unidades básicas de saúde. Esses serviços devem ser levados para perto das famílias em situação de extrema pobreza.

A assistência social presta serviços através de duas modalidades de proteção, sendo a proteção social básica e a proteção social especial, a qual se divide em duas modalidades: média e alta complexidade. Assim, a proteção social básica é prestada através do Centro de Referência da Assistência Social (CRAS), que é "[...] uma unidade pública estatal responsável pela oferta de serviços continuados de proteção social básica de assistência social às famílias, grupos e indivíduos em situação de vulnerabilidade social" (SUAS, 2005, p. 46). O CRAS deve prestar serviços, ofertar benefícios e desenvolver programas e projetos que visem a melhoria das condições de vida das famílias referenciadas, conforme pode ser visualizado neste quadro:

QUADRO 3 - OS SERVIÇOS, BENEFÍCIOS, PROJETOS E PROGRAMAS DO CRAS

\begin{tabular}{|c|c|c|}
\hline Serviços & $\begin{array}{c}\text { Socioeducativo geracionais, intergeracionais e com famílias; Sociocomunitário; } \\
\text { Reabilitação na Comunidade; Outros. }\end{array}$ \\
\hline Benefícios & $\begin{array}{c}\text { Transferência de Renda (Bolsa Família); Transferência de Renda (outros); Benefícios } \\
\text { de Prestação Continuada; Benefícios Eventuais - assistência em espécie ou material; } \\
\text { Outros. }\end{array}$ \\
\hline $\begin{array}{c}\text { Programas e } \\
\text { Projetos }\end{array}$ & $\begin{array}{c}\text { Capacitação e promoção da inserção produtiva; Promoção da inclusão produtiva } \\
\text { para beneficiários do Programa Bolsa Família - PBF e no Benefício de Prestação } \\
\text { Continuada; Projetos e Programas de Enfrentamento à Pobreza; Projetos e Programas de } \\
\text { Enfrentamento à Fome; Grupos de Produção e Economia Solidária; Geração de Trabalho } \\
\text { e Renda; Outros. }\end{array}$ \\
\hline
\end{tabular}

Fonte: Orientações técnicas para o Centro de Referência da Assistência Social, MDS, 2006.

Org.: a autora.

As ações a serem desenvolvidas visam a proteção social básica das famílias que se encontram em situação de vulnerabilidade social e são as seguintes:

Entrevista familiar; Visitas Domiciliares; Palestras voltadas à comunidade ou à fa- mília, seus membros e indivíduos; Grupo: oficina de convivência e de trabalho socioeducativo para famílias, seus membros e indivíduos; ações de capacitação e de inserção produtiva; Campanhas socioeducativas; Encaminhamento e acompanhamento de famílias, seus membros e indivíduos; Reuniões e ações comunitárias; Articulação e fortaleci- 
mento de grupos sociais locais; Atividade lúdica nos domicílios com famílias em que haja criança com deficiência; Produção de material para capacitação e inserção produtiva, para oficinas lúdicas e para campanhas socioeducativas, tais como vídeos, brinquedos, materiais pedagógicos e outros destinados aos serviços socioassistenciais; Deslocamento da equipe para atendimento de famílias em comunidades quilombolas, indígenas, em calhas de rios e em zonas rurais (MDS, 2006, p. 35).

A proteção social especial é prestada pelo Centro Especializado da Assistência Social (CREAS), que é "[...] uma unidade pública estatal responsável pela oferta de serviços continuados de proteção social especial de assistência social às famílias, grupos e indivíduos que se encontram em situação de risco pessoal e social por seus direitos violados" (SUAS, 2005, p. 46). Os serviços prestados nas modalidades de média complexidade visam a orientação e o convívio sociofamiliar e comunitário. Já os de alta complexidade precisam garantir proteção integral para os indivíduos ou para as famílias que se encontram sem referência e, dessa forma, em situação de ameaça. Esses serviços são os seguintes:

A Segurança Alimentar deve ser provida através dos Bancos de Alimentos que são:

\section{QUADRO 4 - A PROTEÇÃO SOCIAL ESPECIAL: MÉDIA E ALTA COMPLEXIDADE EXECUTADA PELO} CREAS

\begin{tabular}{|c|c|c|c|}
\hline $\begin{array}{c}\text { Proteção } \\
\text { Social } \\
\text { Especial }\end{array}$ & $\begin{array}{c}\text { Média } \\
\text { Complexidade }\end{array}$ & $\begin{array}{c}\text { Serviço de orientação e apoio sociofamiliar; Plantão Social; Abordagem de Rua; } \\
\text { Cuidado no Domicílio; Serviço de Habilitação e Reabilitação na comunidade } \\
\text { das pessoas com deficiência; Medidas socioeducativas em meio-aberto (PSC - } \\
\text { Prestação de Serviços à Comunidade e LA - Liberdade Assistida). }\end{array}$ \\
\cline { 2 - 3 } & $\begin{array}{c}\text { Alta } \\
\text { Complexidade }\end{array}$ & $\begin{array}{c}\text { Atendimento Integral Institucional; Casa Lar; República; Casa de Passagem; } \\
\text { Albergue; Família Substituta; Família Acolhedora; Medidas socioeducativas } \\
\text { restritivas e privativas de liberdade (Semi-liberdade, Internação provisória e } \\
\text { sentenciada); Trabalho protegido. }\end{array}$ \\
\hline
\end{tabular}

Fonte: Política Nacional de Assistência Social (PNAS, 2004 p. 38).

Org.: a autora.

Unidades de abastecimento e combate ao desperdício que integram a rede de equipamentos públicos de segurança alimentar e nutricional do governo federal. Auxiliam na distribuição de alimentos do Programa de Aquisição de Alimentos (PAA), atuando também na doação a entidades socioassistenciais do Sistema Único de Assistência Social (SUAS) (MDS, 2013b, s/p).

E também através das Cozinhas Comunitárias, que são "Unidades que produzem e comercializam refeições saudáveis e balanceadas, com produtos regionais, vendidas a preços acessíveis e servidas em locais apropriados e confortáveis" (MDS, s/d, s/p.). Essas unidades devem produzir cerca de cem refeições ao dia e serem oferecidas nas regiões onde existe o maior número de pessoas vivendo em extrema pobreza. Os alimentos preparados nessas cozinhas devem ser oriundos do Programa de Aquisição de Alimentos (PAA) e do Banco de Alimentos.
A Saúde também se utiliza dos critérios do Plano Brasil Sem Miséria para definir e ampliar as suas metas de atendimento. Vale lembrar que ela é um direito universal, porém, uma vez que o poder público como um todo está empenhado no combate à pobreza extrema, todas as políticas planejam as suas ações a partir dos dados do Cadúnico. As ações concretas são as Unidades Básicas de Saúde, o Brasil Sorridente, a Saúde da Família, o Olhar Brasil, a Distribuição de Medicamentos, a Rede Cegonha e a Saúde na Escola. Da mesma forma como as demais políticas públicas, a Educação também se utiliza dos dados do Cadúnico para atender as famílias através do Brasil Alfabetizado e do Mais Educação ${ }^{11}$.

O terceiro eixo do plano é a Inclusão Produtiva urbana e rural. Através dessa inclusão

\footnotetext{
${ }^{11}$ As explicações de cada um desses programas podem ser encontradas no site http://mds.gov.br/assuntos/brasil-sem-miseria/ acesso-a-servicos Acesso dia 18 de agosto de 2016.
} 
o governo pretende proporcionar às famílias em situação de extrema pobreza oportunidades de ocupação e renda, tanto no meio rural quanto urbano, estimulando a produção no campo e a ocupação e renda nas cidades. Das mais de 16 mil famílias que vivem em extrema pobreza, $47 \%$ destas encontram-se no espaço rural do país. Isso significa que o governo precisa fazer com que as ações da política de combate à pobreza atinjam essa população em suas particularidades. Não dá mais para pensar políticas apenas para o meio urbano.

Para a população que vive nos espaços rurais, o governo pretende:

[...] fortalecer as atividades realizadas pelas famílias extremamente pobres da agricultura familiar, aumentando a sua capacidade produtiva e a entrada de seus produtos nos mercados consumidores, através de orientação e acompanhamento técnico, oferta de insumos e de água (MDS, s.d., s/p).

Para que isso ocorra, o governo proporciona assistência técnica à produção agrícola, oferece recursos do fundo perdido para a compra de sementes e ainda garante a construção de cisternas e sistemas simplificados coletivos através do Programa Água para Todos.

No meio urbano vivem $53 \%$ das famílias extremamente pobres. Para essas famílias as ações são: inclusão no mercado de trabalho, "[...] seja por meio do emprego formal, do empreendedorismo ou de empreendimentos da economia solidária" (MDS, s.d., s/p). Note-se que não se trata de ampliar o mercado de trabalho para a inclusão das pessoas em idade produtiva. Nesse sentido, o governo proporciona a oferta de:

[...] qualificação sócio-profissional e intermediação de mão de obra, que visam à colocação dos beneficiários em postos de emprego com carteira de trabalho e previdência assinada, de apoio a microempreendedores e a cooperativas de economia solidária (MDS, s.d., s/p).

A capacitação profissional é realizada por meio do Programa Nacional de Acesso ao Ensino Técnico e Emprego (PRONATEC) ${ }^{12}$ e dos siste-

\footnotetext{
12 "O Programa Nacional de Acesso ao Ensino Técnico e Emprego (Pronatec) foi criado pelo Governo Federal, em 2011,
}

mas " $S$ "13 do país, e ainda pelos institutos tecnológicos de formação técnica. Em se tratando de empreendedorismo, o governo tem como objetivo estimular "[...] a ampliação e o fortalecimento dos pequenos negócios e apoiar o microempreendedor individual (MEI), com prioridade para aqueles que são beneficiários do Bolsa Família" (MDS, s.d., s/p). Para acompanhar esse processo o governo conta com o Serviço Brasileiro de Apoio às Micro e Pequenas Empresas (SEBRAE). $E$, além disso, a inclusão produtiva urbana conta com os bancos públicos quando precisam do microcrédito produtivo.

As ideias da economia solidária "[...] compreendem ações de estímulo à criação de empreendimentos autogestionados, microcrédito produtivo orientado e assistência técnica e apoio à comercialização de produtos e serviços desses empreendimentos" (MDS, s.d., s/p). Essas ações são desenvolvidas em parceria com a Secretaria Nacional de Economia Solidária (SNAES) e do Ministério do Trabalho e Emprego (MTE). Ainda nesse aspecto existe o incentivo à criação de cooperativas de catadores de materiais reciclados, bem como a capacitação profissional desses catadores. São com essas ações que o governo quer acabar com a extrema pobreza no Brasil.

Diante dessa proposta, qual é o papel do Sistema Único de Assistência Social? Quando se faz a Busca Ativa, as equipes dos CRAS identificam as famílias que vivem em situação de vulnerabilidade social, risco ou violação de direitos em cada território e a partir disso fazem os encaminhamentos cabíveis para cada situação encontrada, sendo que o primeiro passo é o registro no Cadastro Único. Quem faz a Busca Ativa são as equipes volantes dos CRAS, para cuja ação o MDS participa como cofinanciador. "A Busca Ativa é uma ação que faz parte da função de Vigilância Social prevista na Política Nacional de Assistência Social (PNAS)" (COLLIN, MASSARANI e MORENO, 2014, p. 352). Através das informações que são coletadas nos territórios

com o objetivo de ampliar a oferta de cursos de educação profissional e tecnológica" Disponível em http://pronatec.mec.gov.br/ institucional/o-que-e-o-pronatec. Acesso dia 07 de maio de 2013

${ }^{13}$ Dois dos sistemas "S" do país são instituições que oferecem capacitação profissional, como o Serviço Nacional de Aprendizagem Industrial (SENAI) e Serviço Nacional de Aprendizagem Comercial (SENAC). 
se conhece mais a realidade local e se pode planejar as ações. O encaminhamento das pessoas se dá não apenas para os serviços e benefícios do SUAS, mas também para aqueles da rede socioassistencial.

No eixo serviços, o SUAS oferta benefícios, programas, projetos e serviços socioassistenciais de Proteção Social Básica e Especial, nas suas duas modalidades (COLLIN, MASSARANI e MORENO, 2014), conforme foi mostrado acima. Para o Eixo garantia de acesso à renda, a Assistência Social oferta três tipos de benefícios socioassistenciais: o Programa Bolsa Família (PBF), o Benefício de Prestação Continuada (BPC) e os Benefícios Eventuais (BE). No Eixo inclusão produtiva, o papel do SUAS é ser facilitador e articulador da oferta pública de qualificação profissional. E é por meio do CRAS que são selecionadas as pessoas para participarem do Programa Nacional de Acesso ao Ensino Técnico e Emprego (PRONATEC), "[...] que oferta cursos gratuitos de formação inicial e continuada voltados para a inserção no mercado de trabalho" (COLLIN, MASSARANI e MORENO, 2014, p. 359). Parte das vagas desses cursos são oferecidas para pessoas que vivem em situação de vulnerabilidade e risco social, e o papel do SUAS é identificá-las. Vale ressaltar que não é o SUAS que promove esses cursos, mas ele participa de forma indireta através do Acessuas Trabalho, que "[...] promove [...] o acesso da população em situação de vulnerabilidade social aos cursos existentes [...]" (COLLIN, MASSARANI e MORENO, 2014, p. 359). O papel do SUAS nesse processo é estruturar as suas ações, tendo por base as seguintes etapas: articulação, mobilização, encaminhamento e monitoramento da trajetória. Portanto, essa é a proposta atual de combate à pobreza no Brasil que envolve diversos ministérios e políticas públicas com ações articuladas e intersetoriais.

\section{Considerações finais}

A perspectiva que orienta as estratégias governamentais de enfrentamento à pobreza no Brasil parte da mesma vertente que aquela das Agências Internacionais, que é o foco no desenvolvimento das capacidades da pessoa em situação de pobreza, numa concepção multidimensional da pobreza. A partir desse viés, combater a pobreza é criar oportunidades para o desenvolvimento de habilidades da pessoa que se encontra nessa situação. Por isso, as ações possuem um viés de desenvolvimento de capacidades para incluir alguns no mercado de trabalho (aqueles que o mercado quiser) e capacitar outros para o empreendedorismo (geração de renda individual), porque o mercado não absorve toda a força produtiva. Não é por acaso que o governo quer enfrentar a pobreza através do aumento da renda per capita, pois isso ajuda a inserir os sujeitos em situação de pobreza no mercado como consumidores. O consumo é fundamental para fazer girar o capital e aumentar o lucro.

Na verdade, faz-se necessário repensar a política econômica atrelada ao trabalho, onde se pudesse ampliar a capacidade de absorção da força de trabalho. E nesse processo o Estado pode intervir, favorecendo a contratação do trabaIhador com carteira assinada, o que lhe garante vários direitos; ampliando o valor real do salário através do controle da inflação; oferecendo mais vagas em cursos superiores para a capacitação dos trabalhadores, mexendo na carga tributária, quando se trata de registrar um trabalhador etc. É importante salientar que capacitar as pessoas, proporcionar acesso aos serviços e políticas públicas e incluí-las numa rede ${ }^{14}$ de proteção social faz parte dos direitos do cidadão e isso deve ser garantido. Fazendo isso, o Estado está apenas cumprindo aquilo que é de sua responsabilidade. Ainda mais o Brasil que tem uma carga tributária que pesa sobre o trabalhador. No entanto, é preciso ter claro que somente essas medidas não tornam possível a erradicação da pobreza na sua essência.

O Plano Brasil Sem Miséria não propõe ações que mexam nas estruturas do sistema capitalista; até porque um país apenas não teria essa capacidade. Seria necessário um empreendimento revolucionário muito maior e mais profundo. O plano é importante no sentido de que identificará a face da pobreza (numericamente falando), incluirá na rede de proteção social pessoas que se encontram em extrema pobreza, até então desconhecidas para o Estado. Isso vai fazer gerar uma série de dados estatísticos,

\footnotetext{
14 Uma rede de proteção social é formada por instituições públicas e privadas que prestam serviços na área das Políticas Públicas.
} 
os quais poderão ser usados futuramente para pensar as políticas públicas, assim como garantir direitos sociais aos cidadãos que se encontram em situação de pobreza. É importante frisar a necessidade de ampliação dos serviços de proteção social como um todo, pois o atendimento efetivo das famílias em situação de pobreza depende de serviços disponíveis. Efetividade na prestação de serviços não significa apenas a ampliação de vagas, mas o aumento da capacidade de oferecer estruturas adequadas e suficientes, produtos no momento que a pessoa precisa, serviços ágeis e eficientes, recursos humanos capacitados e bem remunerados, ou seja, as políticas públicas precisam ser ampliadas, e não apenas repasse de recursos para a esfera privada ou pública com o intuito de mitigar o sofrimento dessa parcela da população. Além disso, a participação popular é fundamental para uma efetiva fiscalização dos serviços prestados e recursos distribuídos, a fim de que a democracia possa crescer e a corrupção possa diminuir. Ser democrático é tornar a coisa pública, de fato pública, onde todo cidadão tenha acesso, tanto a bens e recursos quanto a informações para que possa exercer o controle social. Em todo caso, chama a atenção a forma como se estruturou o Plano em sua articulação com as políticas públicas, Educação, Saúde, Assistência Social, Segurança Alimentar, Habitação etc. É como se o país estivesse se colocando como um todo articulado para o combate à pobreza. O desafio será fazer efetivamente esta engrenagem articulada funcionar com o mesmo objetivo. E ampliar mais ainda essas políticas a fim de atender toda a demanda que será identificada através da Busca Ativa.

Entretanto, o problema está na forma como se mede a pobreza. O corte per capita é baixo, se considerado o seu real valor para o poder aquisitivo das famílias em situação de pobreza, pois para a análise das políticas, as famílias que ultrapassarem esse valor não serão mais consideradas em extrema pobreza. Não seria o Plano Brasil sem Miséria uma forma mais sofisticada de focalização da política de combate à pobreza? Não estaria demonstrando uma preocupação comum com os dados estatísticos por parte do governo e das agências internacionais e uma vez que isso fosse resolvido, o país seria considerado vitorioso por combater a miséria extrema? Mas o que significa ter $R \$ 70,00$ mensais ou $R \$ 70,05$, ou pouco mais? A partir de um viés analítico crítico se percebe que o combate à pobreza não é possível sem mudanças estruturais, articuladas com outras políticas, como a política econômica, por exemplo. Todavia, qual será a influência do Plano Brasil Sem Miséria no combate à pobreza e às desigualdades sociais? Combater a pobreza de forma focalizada e emergencial contribui para a diminuição das desigualdades? São incógnitas a serem problematizadas em pesquisas futuras.

\section{Referências}

ALAYÕN, Norberto. Assistência e Assistencialismo: controle dos pobres ou combate à pobreza? São Paulo: Cortez, 1992;

ANDERSON, Perry. Balanço do neoliberalismo. In.: SADER, Emir e GENTILI, Pablo (Orgs). Pós Neoliberalismo: as Políticas Sociais e o Estado Democrático. $8^{a}$ Ed - Rio de Janeiro: Paz e Terra, 1995;

ANTUNES, Ricardo. Adeus ao Trabalho?: Ensaio sobre as metamorfoses e a centralidade do mundo do trabalho. $7^{a}$ Ed. São Paulo: Cortez; Campinas, SP: Editora da Universidade Estadual de Campinas, 2000;

BRASIL, República Federativa do. Decreto № 7.492, DE 02/06/2011 - DOU 03/06/2011 que institui o Plano Brasil sem Miséria. Brasília, DF, 2011;

Plano Diretor

da Reforma do Aparelho do Estado. Brasília, DF, 1995;

Norma

Operacional Básica do SUAS. (NOB/SUAS). Brasília, DF, 2012;

CABRAL, Paulo Guilherme Francisco, ONCALA, Andrea Arean, GAIVIZZO, Larisa Ho Bech e APOLONI, Renata Corrêa. Programa Bolsa Verde: erradicação da extrema pobreza e conservação ambiental. In.: MDS, Ministério do Desenvolvimento Social e Combate à Fome. O Brasil Sem Miséria. (Organizadores: Tereza Campello, Tiago Falcão e Patrícia Vieira da Costa). Brasília, DF: MDS, 2014;

CAMPELLO, Tereza e MELLO, Janine Mello. O processo de formulação e os desafios do Plano Brasil sem Miséria: por um país rico e com oportunidades para todos. In.: MDS, Ministério do Desenvolvimento Social e Combate à Fome. O Brasil Sem Miséria. (Organizadores: Tereza Campello, Tiago Falcão e Patrícia Vieira da Costa). Brasília, DF: MDS, 2014; 
CEPAL/ ONU. Panorama Social da América Latina. Documento Informativo 2011. Disponível em: http:// www.cepal.org/publicaciones/xml/3/45173/2011-820PSP-Sintese-Lanzamiento.pdf. Acesso em: 12 de jun. 2011;

COLLIN, Denise Ratmann Arruda, MASSARANI, Valéria Maria de e MORENO, Ana Heloísa Viana Silva. O Plano Brasil Sem Miséria e a contribuição da Política de Assistência Social na oferta de serviços para a garantia de necessidades sociais básicas. In.: MSD, Ministério do Desenvolvimento Social e Combate à Fome. O Brasil Sem Miséria. (Organizadores: Tereza Campello, Tiago Falcão e Patrícia Vieira da Costa). Brasília, DF: MDS, 2014;

FALCÃO, Tiago e COSTA, Patrícia Vieira da. A linha de extrema pobreza e o público-alvo do Plano Brasil sem Miséria. In.: MSD, Ministério do Desenvolvimento Social e Combate à Fome. O Brasil Sem Miséria. (Organizadores: Tereza Campello, Tiago Falcão e Patrícia Vieira da Costa). Brasília, DF: MDS, 2014;

IAMAMOTO, Marilda Villela. O Serviço social na contemporaneidade: trabalho e formação profissional. São Paulo: Cortez, 1998;

IAMAMOTO, Marilda Villela. Serviço Social em tempo de capital fetiche: capital financeiro, trabalho e questão social. São Paulo: Cortez, 2007;

IVO, Anete Brito Leal. A reconversão da Questão Social e a Retórica da Pobreza nos anos 1990. In.: CIMADAMORE, Alberto; DEAN, Hartley e SIQUEIRA, Jorge (Orgs). A Pobreza do Estado: Reconsiderando o papel do Estado na luta contra a pobreza global. $1^{a}$ Ed - Buenos Aires: Consejo Latinoamericano de Ciencias Sociales - CLASCO, 2006 p.61-86;

MDS, Ministério do Desenvolvimento Social e Combate à Fome (MDS). Orientação Técnica para o Centro de Referência de Assistência Social (Versão preliminar) - Brasília, 2006;

MDS, Ministério do Desenvolvimento Social e Combate à Fome. Plano Brasil Sem Miséria no seu município. Disponível no site http://www.mds.gov.br/webarquivos/ publicacao/brasil_sem_miseria/cartilha-encontroprefeitos-final-18022013.pdf Acesso dia 18 de agosto de 2016. Brasília, DF, 2013a;

Informações sobre o Plano Brasil Sem Miséria. Disponíveis no site http://www. brasilsemmiseria.gov.br/busca-ativa Acesso dia 15 de fevereiro de 2013b;
NOGUEIRA, Marco Aurélio. Um estado para a Sociedade Civil: temas éticos e políticos da gestão democrática. $2^{\mathrm{a}}$ ed. São Paulo: Cortez, 2005;

ONU, Organização das Nações Unidas. Estado de Las Ciudades: Rumbo a una nueva transición urbana. Programa de las Naciones Unidas para los Asentamientos Humanos, ONU-Habitat. Agosto, 2012. Disponível em http://estaticog1.globo.com/2012/08/21/ Estado-de-las-Ciudades-de-America-Latina-y-elCaribe-2012.pdf acesso dia 13 de fevereiro de 2013;

PEREIRA, Camila Potyara. A pobreza, suas caudas e interpretações: destaque ao caso brasileiro. In.: Revista Ser Social. (n 18, p.229-252 - jan/jun). Brasília, 2006;

PNAS, Política Nacional de Assistência Social. República Federativa do Brasil. Brasília - DF, 2004;

SEN, Amartya. Desenvolvimento como liberdade. (Tradução Laura Teixeira Motta; revisão técnica Ricardo Doniselli Mendes) São Paulo: Companhia das Letras, 2000;

SILVA e SILVA, Maria Ozanira da. O Serviço Social e o Popular: resgate teórico-metodológico do projeto profissional de ruptura. $4^{\circ}$ ed. São Paulo: Cortez, 2007;

SIQUEIRA, Luana Souza. Desenvolvimento e pobreza: uma análise crítica. In.: Revista Temporalis (ano 12, n²4, p. 353-384, jul/dez). Brasília, DF, 2012;

STEIN, Rosa Helena. Pobreza e desigualdade na América Latina sob o olhar dos organismos internacionais. In.: Revista Ser Social ( $n^{\circ} 18$, p.79125, jan-jun). Brasília, DF, 2006;

SOTO, Silvia Fernández. "El concepto de pobreza en la teoría marxista". In: Serviço Social \& Sociedade. Revista Quadrimestral de Serviço Social Ano XXIV-n ${ }^{\circ}$ 73- marco 2003. Edit. Cortez, São Paulo, Brasil, 2003, p.5-22;

SUAS, Sistema Único de Assistência Social. MPAS, Brasília - DF: 2005;

YAZBEK, Maria Carmelita. Classes subalternas e assistência social. $4^{\mathrm{a}}$ Ed - São Paulo: Cortez, 2003;

YASBEK, Maria Carmelita. Pobreza no Brasil contemporâneo e formas de seu enfrentamento. In.: Serviço Social \& Sociedade, no. 110. São Paulo: Cortez, 2012. Disponível em: http://www. scielo.br/scielo.php?script=sci_issuetoc\&pid=0101$662820120002 \&$ Ing=pt\&nrm=iso>. 